\title{
O ESPAÇO DA EDUCAÇÃO FÍSICA NA ESCOLA: UM ESTUDO SOBRE OS CONTEÚDOS DAS AULAS NO ENSINO MÉDIO
}

\author{
Alenir de Pinho Romoaldo Cordovil \\ Universidade Federal de Mato Grosso, Mato Grosso, Cuiabá, Brasil \\ Cleomar Ferreira Gomes \\ Universidade Federal de Mato Grosso, Mato Grosso, Cuiabá, Brasil \\ Evando Carlos Moreira \\ Universidade Federal de Mato Grosso, Mato Grosso, Cuiabá, Brasil \\ Marcia Cristina Rodrigues da Silva \\ Universidade Federal de Mato Grosso, Mato Grosso, Cuiabá, Brasil
}

\begin{abstract}
Resumo
A pesquisa investigou as expectativas dos alunos de uma escola pública estadual mato-grossense em relação aos conteúdos ensinados nas aulas de Educação Física no Ensino Médio. Empregamos a abordagem qualitativo-descritiva, com a análise do plano de ensino da professora, observações de aula e questionários semiestruturados. Os resultados revelam a desvalorização dessa disciplina no espaço escolar, apontam para a necessidade de reflexão sobre possibilidades curriculares e metodológicas a serem empreendidas nas aulas de Educação Física no Ensino Médio, de maneira a contemplar os interesses e necessidades dos alunos.
\end{abstract}

Palavras-chave: Expectativas. Educação Física. Ensino Médio.

\section{Introdução}

Este trabalho tem um olhar sobre a significativa perda de "espaço" da Educação Física no Ensino Médio que envolve a conflituosa facultatividade do aluno, a redução da quantidade de aulas, a rotatividade de alunos, a presença marginalizada no currículo escolar e a fragilidade da legitimidade pedagógica que justifique sua importância na formação do aluno.

A partir das questões relacionadas à perda de "espaço", em especial, a necessidade de autonomia, capacidade reflexiva e transformadora do professor em lidar com o ensino das práticas corporais na escola, de forma que possa defender o quê, quando e para que ensinar, surgiu uma indagação. Será que os conteúdos ensinados nas aulas de Educação Física no Ensino Médio atendem as expectativas dos alunos, de modo que reconheçam a contribuição na sua formação humana, e valorizem a disciplina no espaço escolar?

Aparentemente a perda de "espaço" se relaciona à ausência de progressão e continuidade dos conteúdos ensinados nas aulas de Educação Física (PALMA; OLIVEIRA; PALMA; 2010). A respeito disso, diversos estudiosos e orientações (BRASIL, 2006; PALMA; OLIVEIRA; PALMA, 2010; DARIDO, 2005; KUNZ, 2004) apontam que o professor tem a possibilidade de construir sua própria sistematização de conteúdos, adequando-os à realidade 
de sua região, com seus próprios contextos culturais, considerando as demandas educacionais e os sujeitos a quem tais conteúdos serão ensinados.

Definimos como objetivo compreender as expectativas dos alunos de uma escola pública estadual mato-grossense em relação aos conteúdos ensinados nas aulas de Educação Física no Ensino Médio que revelam a desvalorização dessa disciplina no espaço escolar. Mais especificamente: identificar as expectativas dos alunos sobre as aulas de Educação Física no Ensino Médio; relacionar suas expectativas com os elementos que contribuem para desvalorização da disciplina; refletir sobre possibilidades curriculares e metodológicas a serem empreendidas nas aulas de Educação Física no Ensino Médio que possam atender aos interesses dos alunos e contribuir para sua formação humana.

\section{Metodologia da pesquisa}

A pesquisa foi realizada como uma ação de investigação diagnóstica de um subprojeto do Programa Institucional de Bolsa de Iniciação à Docência - PIBID, que atua com o Ensino Médio em Cuiabá - MT, a fim de conhecer a organização pedagógica da escola, o perfil do aluno do Ensino Médio e como ocorrem as aulas de Educação Física, para assim, subsidiar as ações de intervenção da equipe no biênio 2013-2014.

Para Minayo (2007, p. 27) "[...] a análise qualitativa não é uma mera classificação de opinião dos informantes, é muito mais. É a descoberta dos seus códigos sociais a partir das falas, símbolos e observações". Essa proposição fundamentou a abordagem metodológica da pesquisa, caracterizando-a como qualitativa de tendência descritiva.

A escola investigada é da rede pública estadual de Cuiabá-MT, atende cerca de mil alunos do Ensino Médio, distribuídos nos três períodos, tendo adotado a proposta de Ensino Médio Inovador. As aulas de Educação Física são oferecidas no contraturno escolar e ocorrem regularmente às terças-feiras para as turmas de $1^{\circ}$ ano. Foi acompanhada a turma do $1^{\circ}$ ano $\mathrm{D}$, com um total de 17 alunos.

\section{Instrumentos de coleta de dados}

A coleta de dados ocorreu entre os meses de março e maio de 2013 e 2014, sendo realizada da seguinte forma: um mapeamento diagnóstico que incluiu a aplicação de questionário construído coletivamente pela equipe do subprojeto, aos alunos, no horário regular de aula; observações não participantes das aulas com base num roteiro de investigação; estudo do plano de ensino da professora.

O questionário compreendia 30 questões, divididas em duas etapas: perfil socioeconômico dos pesquisados e a visão do aluno sobre a Educação Física no Ensino Médio. Vale salientar que em algumas perguntas os alunos tinham a possibilidade de assinalar mais de uma opção.

Neste trabalho aprofundamos nossa análise em relação à segunda etapa do questionário, com nove questões abertas e quatro fechadas, com os alunos do $1^{\circ}$ ano $\mathrm{D}$, identificados por códigos, sendo: "1" correspondendo ao ano, "D" à turma, "M" ou "F" identificando o gênero e, por fim " $01,02 \ldots$ ” que diz respeito ao número do questionário compilado.

\section{A Turma do $1^{\circ}$ Ano "D"}


A turma do $1^{\circ}$ ano " $\mathrm{D}$ " era composta por 17 alunos, sendo dez meninos e sete meninas, com idade entre 14 e 16 anos, sem qualquer deficiência física ou intelectual. Destes, cerca de $70 \%$ estão sob a responsabilidade dos pais biológicos. Todos os alunos responderam ao questionário da pesquisa, porém, apenas oito alunos frequentavam as aulas de Educação Física.

Os dados revelaram que apenas quatro alunos exerciam atividade remunerada esporadicamente. Nenhum dos alunos residia nas proximidades da escola e todos utilizavam transporte público, o que delineou uma possível causa para a não participação nas aulas de Educação Física, que ocorrem no contraturno.

\section{Análises e discussão de dados}

As análises da pesquisa foram organizadas em unidades representativas que expressam as expectativas dos alunos sobre os conteúdos ensinados nas aulas de Educação Física, a saber: motivações e desmotivações para as aulas de Educação Física; preferências e recorrências sobre conteúdos e práticas nas aulas de Educação Física; importância dos conhecimentos da Educação Física para vida; entre o que há e o que pode haver: quais são as expectativas?

\section{Motivações e Desmotivações para as aulas de Educação Física}

Os alunos foram indagados sobre "Você gosta e se sente motivado a participar das aulas de Educação Física? Por quê?". Percebemos que, metade dos alunos (oito alunos) participam das aulas, motivados pelo interesse/importância do Exercício Físico, Esporte e Saúde:

Sempre é bom se exercitar, e também eu gosto de fazer. (1DM01)

Eu gosto de jogar bola. (1DM04)

Eu gosto de praticar esportes. (1DM05)

A gente pratica esporte e isso faz bem para saúde. (1DM07)

Mas, o que é o "exercício físico" na percepção dos alunos? Há consenso de que o exercício físico faz bem para a saúde, muitas vezes, respaldado pelo senso comum ou propagandas midiáticas, e neste caso, não parece ser diferente. Aparentemente, ocorreu nas falas dos alunos a reprodução do discurso hegemônico de ordem médica e higienista, em que prevalece a ideia da utilização dos exercícios físicos para a promoção da saúde, sem maior aprofundamento dos implicadores sociais, culturais e econômicos sobre o assunto.

O mesmo ocorre com o elemento "saúde", que aparece intimamente ligado à prática de exercícios físicos. De fato, há "[...] um discurso que considera que a atividade física regular poderia contribuir para o projeto de autonomia do indivíduo, pois ele estaria mais apto para realizar suas tarefas do dia-a-dia" (PALMA, 2001, p. 32). Entendemos que essa deve ser uma prática que faça parte da vida do sujeito "dentro" ou "fora" da escola. Mas, para além do 
exercitar-se, formar para autonomia perpassa pela discussão dos direitos sociais e cidadania, que podem ser assuntos tratados pelo professor de Educação Física com o aluno do Ensino Médio, ao discutir as políticas públicas de saúde, lazer e esporte.

No tocante ao "esporte", os apontamentos dos alunos foram esclarecidos à luz dos relatos de observação, que retrataram a organização pedagógica das aulas de Educação Física, o que possivelmente fundamenta a compreensão unilateral dos alunos, como se pode perceber na nota que segue:

No horário especificado, os alunos estabelecem o que será feito na aula, que geralmente é a prática do futsal. A bola já estava em poder dos alunos sem a presença da professora, sendo que quando a mesma chegou o jogo já estava acontecendo, pois, os alunos se dividiram em times de camisa e sem camisa... Definiram as regras do jogo e como se daria a partida, sendo que o jogo seria finalizado com dez minutos de duração ou se um dos times fizesse dois gols. Tudo transcorria sem a intervenção da professora.

Identificamos que o conteúdo privilegiado nas aulas é o esporte, em específico, o futsal. Contudo, a não participação ativa da professora no sentido de gerir a aula, assumindo seu papel pedagógico, pode ter colaborado para a compreensão da aula de Educação Física no Ensino Médio como passatempo, recreação, momento de encontro entre os amigos.

Concordamos que,

[...] a prática da Educação Física contribua para o desenvolvimento de adolescentes que dela fazem parte, permitindo que seja mais do que um simples jogo ou um momento de relaxamento e descontração como muitos afirmam, mas um espaço de construção de conhecimentos e significados (MOREIRA; PEREIRA; LOPES, 2009, p. 138).

Não negamos a importância da sociabilidade nessa fase da vida. Dayrell (2007, p. 1110), aponta que esta “[...] se desenvolve nos grupos de pares, preferencialmente nos espaços e tempos do lazer e da diversão, mas também presente nos espaços institucionais como a escola ou mesmo o trabalho", sendo assim, é esperado que nesses espaços os jovens construam laços com suas "turmas" de amigos e estabeleçam trocas de ideias em momentos divertidos.

No entanto, conforme explicita Vago (2009, p. 26):

Escola não é clube. Escola não é academia de ginástica. Escola não é centro de treinamento esportivo. A escola não é a rua, ou a praça do bairro. Escola não é tempo nem "equipamento" de lazer. Embora possa estabelecer relações com todos esses lugares, a escola é um tempo e um lugar singular, que não pode ser nem confundido com (nem substituído por) nenhum desses.

Esses apontamentos nos fazem refletir que a finalidade da escola é mais do que um "lugar" reservado para entreter os alunos e a aula de Educação Física Escolar não pode ser apenas um momento para descontração e lazer, embora, reconhecemos que seus conteúdos possuem uma função socializadora.

A presença massiva do esporte na aula se manifestou no plano da prática, da técnica, 
do jogar em si... Infelizmente, não há a discussão do esporte como fenômeno social e cultural. Muito menos como uma expressão de diferentes modos de jogar, pois não há direcionamento pedagógico que estimule outras formas de jogar que valorizem os princípios da inclusão e respeito à diversidade.

O esporte que os alunos "falam" lembra o modelo olímpico, processado pela mídia e reproduzido pela prática pedagógica da professora, o que contraria as possibilidades de "[...] compreensão crítica das diferentes formas da encenação esportiva, os seus problemas vinculados ao contexto sociopolítico" (KUNZ, 2004, p. 73).

Em relação à prática pedagógica da professora se percebeu que apesar de existir um planejamento de ensino, este não se materializa no cotidiano das aulas de Educação Física. $\mathrm{O}$ seu papel se resume em realizar o apontamento de frequência diária dos alunos presentes no decurso da aula - sendo esta uma prática comum utilizada como forma de avaliação, conforme o comentário do aluno 1DM05:

Só vir que ganha ponto... presença é pontuação.

O proceder pedagógico da professora é discutido por Darido (2005), ao afirmar que muitos profissionais ainda seguem a concepção recreacionista buscando a participação de todos ativamente, colocando o professor na posição de figura de apoio que apenas acata as sugestões dos alunos quanto às quais atividades serão aplicadas nas suas aulas.

A produção acadêmica da Educação Física Escolar sugere que professor leve os seus alunos a "[...] pensar, desenvolver a reflexão, entender o que faz, raciocinar cientificamente e ter uma independência de pensamento" (BOAVENTURA, 2007, p. 6). O respeito à autonomia do sujeito é demonstrado quando se permite "voz" aos alunos por meio do planejamento participativo, fazendo com se sintam responsáveis pela produção do conhecimento (BOAVENTURA, 2007). O aluno participa consciente da construção da aula capaz de atender as suas expectativas, possibilitando elaborar sentido ao que se faz na aula e na escola, a partir da valorização da sua capacidade crítica de reflexão, o que pode ser caracterizado como uma ação em favor do protagonismo juvenil.

Outra faceta relevada é concernente aos motivos para não participação das aulas de Educação Física no Ensino Médio (nove alunos). Esses apresentam como motivos para não frequência, entre outros, "o contraturno", conforme manifestações a seguir:

Eu não tenho tempo para vir à escola fazer educação física. (1DM02)

Sou cursante, então não venho à educação física. (1DM09)

Entendemos que alocar as aulas fora do turno regular favorece o distanciamento da Educação Física das demais disciplinas curriculares, impossibilitando o processo de interdisciplinaridade, propiciando o indesejado esvaziamento nas aulas, além de se constituir uma ameaça à sua identidade enquanto componente curricular obrigatório.

A Educação Física no contraturno pode se constituir um dilema se não for pensada de "dentro" para "fora", a partir dos sujeitos, contemplando suas expectativas e necessidades educacionais. Lidamos com uma categoria juvenil, que compartilha ansiedades em muitos âmbitos da vida "fora" da escola e que, certamente, se depara com incertezas também "dentro" do ambiente escolar. Portanto, ao haver apenas motivo para retornar à escola, sem 
que haja comprometimento com experiências e conteúdos significativos, acaba por desacreditar a Educação Física como disciplina curricular.

O contraturno apareceu como um fator preponderante para a não participação nas aulas. Isso fica claro quando notamos respostas, tais como:

[...] moro longe e cansa ir para a casa e voltar para a escola de novo (1DF02).

Há também aquele que utiliza o tempo da aula de Educação Física para a realização de outras atividades escolares, como cursos preparatórios para o ENEM, Informática, Formação Técnica, dentre outros. Tais considerações nos levam a pensar o quanto o contraturno é um fator que desmotiva a participação dos alunos nas aulas de Educação Física nessa escola.

Ao considerar que a proposta de Ensino Médio Inovador “"[...] pressupõe uma perspectiva de articulação interdisciplinar, voltada para o desenvolvimento de conhecimentos - saberes, competências, valores e práticas" (BRASIL, 2009, p. 16), resta-nos avaliar: Qual é o "espaço" da Educação Física nessa escola? Quais vínculos a Educação Física estabelece com a proposta de Ensino Médio Inovador? Quais os motivos de se ter uma disciplina alocada fora do horário de aula regular se isso não atende os princípios dessa organização curricular?

O esvaziamento das aulas é claramente percebido com um número reduzido de alunos aliado à rotatividade, fatores que dificultam a aprendizagem e prejudicam o estabelecimento de uma sequência pedagógica de conteúdos. Respostas como a do aluno 1DM06, que afirma que não existe nada que o interesse além do futsal, revelam que a Educação Física que se tem nesta escola não tem deixado uma impressão significativa. As respostas ainda confessam uma ausência de conteúdos relevantes para a formação do aluno do Ensino Médio, o que, por conseguinte, não apresenta motivação para participar das aulas.

Por outro lado, a mudança da realidade de ensino da Educação Física na escola pesquisada não se resume ao simples fato de alocar as aulas de Educação Física no turno regular de ensino, isso apenas garantiria a presença dos alunos nas aulas. Nesse sentido, não se contribui para a legitimação da Educação Física, como componente curricular, a menos que o professor assegure aos alunos "[...] a oportunidade de vivenciarem o maior número de práticas corporais possíveis. Ao realizarem a construção e vivência coletiva dessas práticas, estabelecem relações individuais e sociais, tendo como pano de fundo o corpo em movimento" (BRASIL, 2006, p. 224).

\section{Preferências e recorrências sobre conteúdos e práticas nas aulas de Educação Física}

Identificamos as preferências dos alunos sobre o que lhes é ofertado nas aulas de Educação Física, indagando: "O que você mais gosta de fazer nas aulas de Educação Física?" As respostas dos alunos foram organizadas no quadro 1 abaixo: 


\begin{tabular}{|c|c|c|}
\hline CÓDIGO & O QUE GOSTA DE FAZER NAS AULAS & \multirow{2}{*}{ CATEGORIAS } \\
\hline 1DM01 & Jogar basquetebol & \\
\cline { 1 - 2 } 1DM05 & Jogar basquetebol, futsal e handebol & \multirow{2}{*}{ Esporte } \\
\hline 1DM07 & Jogar futsal, vôlei, etc. & \\
\hline 1DM10 & Exercícios, vôlei, futsal e etc. & \\
\hline 1DF01 & Futsal, vôlei, handebol & \\
\hline 1DF02 & Basquetebol e vôlei & \\
\hline 1DF04 & Vôlei e handebol & \\
\hline 1DF06 & Jogar bola & \\
\hline
\end{tabular}

Quadro 1 - Os conteúdos preferidos pelos alunos nas aulas de Educação Física do Ensino Médio

Nota: Construção dos autores

O esporte foi apontado pelos alunos como conteúdo que mais gostam de praticar nas aulas de Educação Física e, de fato, não deve ser extirpado desse contexto, mas, visto como uma das possibilidades de alcançar os objetivos de formação do aluno na disciplina.

A pedagogia do esporte, segundo Kunz (2004, p. 63), “[...] se refere apenas ao esporte que tem como conteúdo o treino, a competição, o atleta e o rendimento esportivo". E, isso é o que tem sido preconizado no ambiente escolar, apesar do crescente descontentamento apreciado nas discussões da área. O autor ressalta a necessidade de um "conceito amplo" que considere as "[...] formas de manifestação e de forma contextualizada, em que ser humano e movimento são relevantes ao agir e pensar", sendo "dentro" ou "fora" da escola, pois o movimento existe mesmo que não esteja no contexto escolar (KUNZ, 2004, p. 67).

Daquilo que é apontado pelos alunos, como gosto/preferência, entendemos que estes, unidos a outras formas de manifestação corporal, poderiam atender os documentos e diretrizes curriculares para Educação Física (BRASIL, 2006; MATO GROSSO, 2010) e contemplarem o plano de ensino da professora que, para os primeiros anos do Ensino Médio, propõe como objetivos: estimular a prática de atividade física, informando seus benefícios e a necessidade do movimento e do exercício no mundo moderno; desinibir e desbloquear; conhecer e valorizar, apreciar e desfrutar de algumas das manifestações da cultura corporal de movimento.

Os objetivos pedagógicos elencados no plano de ensino da professora não excluem os esportes, que poderiam ser amplamente explorados, porém, ao mencionar o estímulo à prática de atividades físicas apontam para a necessidade de contextualização desse conteúdo, algo não observado nas aulas. Dessa forma, o trato pedagógico do conteúdo pode ou não dar significado e motivar a participação dos alunos nas aulas.

Destaca-se que mesmo na quadra, ao ar livre ou em outros espaços, os conteúdos da Educação Física podem ser apresentados e vivenciados pelos alunos a fim de que percebam a sua finalidade e construam significados para sua formação.

Dayrell (2007, p. 1118) reconhece que “[...] a escola, por si só, não consegue responder aos desafios da inserção social dos jovens, tendo poder limitado na superação das desigualdades sociais e nos processos de emancipação social". Mesmo assim, é necessário que a prática pedagógica atenda às necessidades, preferências e anseios dos alunos, que por serem jovens estão repletos de expectativas acerca de seu futuro. Uma pedagogia crítica, pensada a partir do aluno, seria aceitável. 


\section{Importância dos conhecimentos da Educação Física para vida}

Na busca de entender a importância da Educação Física na formação humana dos alunos do Ensino Médio, da turma do $1^{\circ} \mathrm{D}$, nesta escola, passamos a analisar três questões contidas na segunda etapa do instrumento de investigação, que são: "Atualmente a Educação Física tem importância para você? Por quê?"; "Você pratica alguma atividade no seu dia a dia fora da escola?"; "Você aplica seus conhecimentos de Educação Física no seu dia a dia?".

$\mathrm{O}$ quadro 2 tece um paralelo entre aquilo que os alunos vivenciam nas aulas com o que, no entendimento de cada um, tem importância em seu cotidiano "dentro" e "fora" da escola.

\begin{tabular}{|c|c|c|c|}
\hline CóDIGOS & $\begin{array}{c}\text { ATUALMENTE A } \\
\text { EDUCAÇÃO FÍSICA TEM } \\
\text { IMPORTÂNCIA PARA } \\
\text { VOCÊ? POR QUÊ? }\end{array}$ & $\begin{array}{c}\text { VOCÊ PRATICA } \\
\text { ALGUMA ATIVIDADE } \\
\text { NO SEU DIA-A-DIA } \\
\text { FORA DA ESCOLA? }\end{array}$ & $\begin{array}{c}\text { VOCÊ APLICA SEUS } \\
\text { CONHECIMENTOS DE } \\
\text { EDUCAÇÃO FÍSICA NO } \\
\text { SEU DIA-A-DIA? }\end{array}$ \\
\hline 1DM01 & $\begin{array}{l}\text { Sim, porque não tenho onde } \\
\text { praticar esporte e nem educação } \\
\text { fisica }\end{array}$ & 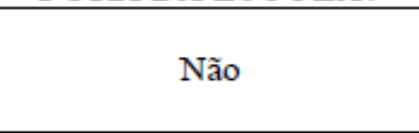 & 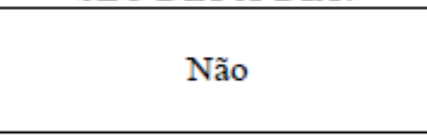 \\
\hline 1DM02 & Não, porque eu não tenho tempo & $\begin{array}{c}\text { Sim, futsal uma vez por } \\
\text { semana }\end{array}$ & Sim \\
\hline $1 \mathrm{DM} 03$ & Não, porque eu não tenho tempo & $\begin{array}{c}\text { Sim, Karatê, segunda, } \\
\text { quarta e sexta }\end{array}$ & $\mathrm{x}$ \\
\hline 1DM04 & Não. Porque eu trabalho & $\begin{array}{c}\text { Sim, jogo bola em um time } \\
\text { no bairro }\end{array}$ & Sim \\
\hline 1DM05 & $\begin{array}{l}\text { Sim, porque futuramente quero } \\
\text { ser um jogador da NBA }\end{array}$ & $\begin{array}{l}\text { Sim, Academia, basquete e } \\
\text { futsal }\end{array}$ & $\begin{array}{c}\text { Sim, o respeito com o } \\
\text { próximo }\end{array}$ \\
\hline 1DM06 & $\begin{array}{c}\text { Sim, porque está sendo um } \\
\text { passatempo }\end{array}$ & $\begin{array}{c}\text { Sim, futebol de campo, } \\
\text { atletismo }\end{array}$ & Sim \\
\hline 1DM07 & $\begin{array}{c}\text { Sim, porque praticar esporte faz } \\
\text { bem }\end{array}$ & Não & Não \\
\hline 1DM08 & Não, sem importância & Não & Sim \\
\hline 1DM09 & Não venho & $\begin{array}{c}\text { Sim, Jogo bola com os } \\
\text { amigos }\end{array}$ & Sim, quase todos os dias \\
\hline $1 \mathrm{DM} 10$ & $\begin{array}{l}\text { Sim, pois em vez de estarmos nas } \\
\text { ruas, nós estamos na escola } \\
\text { fazendo exercícios que é bom pra } \\
\text { saúde }\end{array}$ & Não & Sim, porque é bom \\
\hline 1DF01 & $\begin{array}{c}\text { Sim, porque não sou de praticar } \\
\text { muitos esportes }\end{array}$ & Não & Alguns \\
\hline 1DF02 & Não & Não & $\mathrm{X}$ \\
\hline 1DF03 & $\begin{array}{l}\text { Não, pois não tenho muito tempo } \\
\text { e também me canso muito }\end{array}$ & Não & $\begin{array}{l}\text { Não, porque geralmente não } \\
\text { faço muitos exercícios }\end{array}$ \\
\hline 1DF04 & $\begin{array}{c}\text { Sim, pois ajuda a gente a dividir } \\
\text { as coisas }\end{array}$ & Não & Sim \\
\hline 1DF05 & Não muito, pois quase não venho & Sim, academia & Não \\
\hline 1DF06 & $\dot{E}$ importante, mas não sei porque & Não & Não \\
\hline 1DF07 & Sim, mas não gosto de fazer & Não & Não \\
\hline
\end{tabular}

Quadro 2 - A importância da Educação Física na formação do aluno de Ensino Médio Nota: Construção dos autores 
As respostas destacam a importância da Educação Física por diversos fatores, sem fornecer uma definição clara sobre o seu papel pedagógico no Ensino Médio, conforme aponta o aluno 1DF06 que diz:

\section{É importante, mas não sei por que.}

Por outro lado, os alunos atribuem importância à Educação Física quando a relacionam com a promoção da saúde e lazer. Isso ocorre por compartilharem do conceito de que as aulas de Educação Física se destinam a prática de exercícios físicos, que por sua vez, estão vinculados à boa saúde, como percebemos na resposta do aluno 1DM07:

Sim, porque praticar esporte faz bem.

O significado restrito sobre as aulas de Educação Física pode ter sido o "gatilho" para a não importância dada à disciplina pelos alunos do Ensino Médio. O que possivelmente explique o esvaziamento das aulas, pois, quando não se vê importância em algo, tampouco existe o comprometimento com aquilo. Pressupomos que isso se deve ao exposto em relação à atuação da professora, estando ali como figura simbólica apenas para acompanhar os alunos, o que de fato, não concretiza e nem legitima a Educação Física no Ensino Médio.

Santin (2003, p. 37) aponta para a canseira ou 'tédio' de alunos e professores perante a uma compreensão de Educação Física como mecânica, que resulta “[...] automaticamente, no esporte, na competição ou numa técnica de manter a saúde".

A organização da prática pedagógica evidenciada nas aulas indica que a Educação Física tem perdido "espaço" por não ter sido capaz de se legitimar enquanto componente curricular, de modo a problematizar sua função educativa e propor práticas pedagógicas que contemplem as necessidades de seus alunos.

Entre as atividades vivenciadas pelos alunos "fora" do ambiente escolar, estão práticas corporais relacionadas ao esporte, às lutas, a socialização como o "jogo de bola com os amigos" ou "time do bairro" e à atividade física em academia. Ao conhecer essas expressões e modos de viver a corporeidade na juventude, que se incluem no plano de ensino da professora e são recomendadas como temáticas para aprofundamento crítico nas aulas de Educação Física no Ensino Médio pelas diretrizes curriculares (BRASIL, 2006), entendemos que tais expressões corporais diagnosticadas pela pesquisa devam ser viabilizadas e tencionadas através de discussão crítica e inseridas no cotidiano de vida dos alunos, bem como, nas aulas de Educação Física no Ensino Médio.

Ao procurar conhecer como os alunos entendem aplicar os conhecimentos adquiridos nas aulas de Educação Física, em seu dia a dia, evidenciamos que se mostram aparentemente alheios aos conhecimentos de Educação Física presentes "fora" do ambiente escolar, ou não reconhecem sua importância no seu cotidiano, como se pode perceber na análise das respostas sem aprofundamento, opostas ao que se esperava, em se tratando de uma pergunta aberta. Entre as respostas, destacamos a afirmação do aluno 1DM05, que fez referência ao "respeito com o próximo". Um comentário que denota um "componente de conduta" (TOLEDO; VELARDI; NISTA-PICCOLO, 2009, p. 55).

Entre o que há e o que pode haver: quais são as expectativas? 
Debruçamo-nos sobre as expectativas dos alunos com base na pergunta aberta "O que você gostaria de aprender nas aulas de Educação Física?”, para a qual os alunos poderiam indicar objetivamente uma ou mais expressões corporais almejadas, que poderiam ser vivenciadas nas aulas de Educação Física no Ensino Médio. Essa questão foi produzida com base na proposição de Moreira (2014) que foi avaliada pelos pesquisadores e adaptada à realidade do contexto de ensino da escola.

As alternativas escolhidas pelos alunos foram organizadas em cinco grandes grupos, sendo: Esporte, Esportes de Aventura, Lutas, Ginásticas e Danças. Esses grupos representam as escolhas dos alunos, conforme ilustração 1, a seguir:

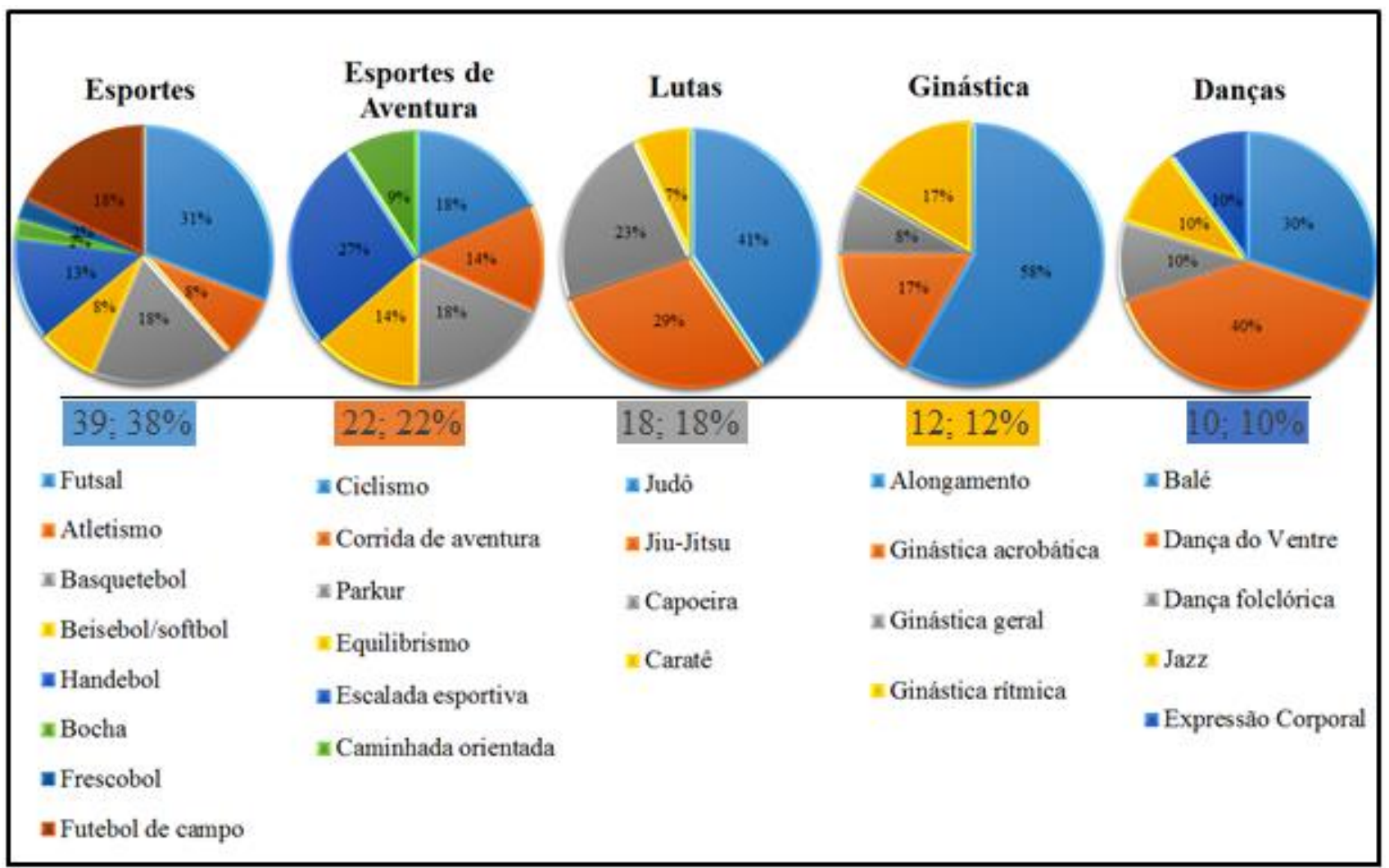

Ilustração 1: Expectativas dos alunos em relação aos conteúdos das aulas de Educação Física

\section{Nota: Construção dos autores}

As respostas obtidas esclarecem que os alunos não rejeitam o "esporte". Esse foi o conteúdo mais citado por eles, porém o diversificam ao indicar outras modalidades esportivas, algumas não tão populares e passíveis de serem adequadas ao contexto escolar. O que indica a possibilidade de experimentação, como a "[...] tematização do seu conteúdo específico, uma compreensão crítica das práticas esportivas, potencializando os sujeitos a estabelecer vínculos com o contexto sociocultural em que estão inseridos" (CARLAN; KUNZ; FENSTERSEIFER, 2012, p. 56).

Para além de uma Educação Física esportivizada, se o desejo é de que a disciplina seja valorizada e legitimada, é preciso que esta responda aos anseios dos alunos, a partir de uma construção compartilhada que reflita as orientações dos documentos curriculares e que as 
expectativas dos alunos sejam o destaque no planejamento das aulas, ou seja, aquilo que se insere entre seus interesses e demandas pessoais, sociais e culturais.

A segunda categoria mais requisitada foi a dos "Esportes de Aventura", seguida das "Lutas". Conteúdos como esses podem ser amplamente abordados e explorados nas aulas de Educação Física, em especial, se forem tratados em parceria com os alunos, tornando-os corresponsáveis pelo próprio aprendizado e dessa forma, favorecendo a construção do conhecimento e o estímulo para sua prática.

Não que haja uma forma pronta e acabada para a adequação de conteúdos nas aulas, porém, constituindo o planejamento de ensino a partir de uma reflexão sobre a diversidade de temáticas existentes, o professor tem a possibilidade de oferecer uma prática pedagógica significativa que seja equivalente àquilo que se espera dele e que é desejado pelos alunos.

Quando analisamos as expectativas dos alunos de maneira mais profunda, concluímos que as categorias mais almejadas não são impossíveis de serem realizadas, mas, implicam em ações de planejamento participativo dos conteúdos e ações pedagógicas em que devem estar envolvidos tanto os professores quanto os alunos. "Todas as ações desenvolvidas pela escola devem integrar-se às necessidades de seus membros, buscando sempre uma construção coletiva e participativa" (MOREIRA; PEREIRA; LOPES, 2009, p. 138). Os comentários dos alunos apontam para um caminho de mudanças quando apresentam suas expectativas, assinalando para a necessidade de se explorar "novos" conteúdos e não somente os mais conhecidos, mostrando que estão abertos a "novas" vivências.

Os conteúdos citados pelos alunos poderiam ser abordados nas aulas, inseridos e/ ou adaptados a partir de diversas vivências no contexto da disciplina, mesmo porque, ao se tratar de uma disciplina distinta, peculiar, como é o caso da Educação Física, "[...] há uma "liberdade"/ flexibilidade maior para programar e organizar sua prática pedagógica" (BOSSLE, 2002, p. 36, grifo do autor).

As reflexões sobre os apontamentos dos alunos, nos levam a compreender que de fato, temos ampla possibilidade de um fazer pedagógico coerente e equivalente às expectativas dos alunos, levando à concretude de nossas ações, a serem implementadas nas aulas de Educação Física no Ensino Médio.

\section{Considerações}

Os resultados nos levam a concluir que se faz necessário investir em mudanças, tanto no conceito da escola como no do professor para, então, atingir os alunos, passando a alcançar a almejada valorização da disciplina no contexto escolar, a fim de refletir sobre possibilidades curriculares e metodológicas a serem empreendidas nas aulas de Educação Física no Ensino Médio que venham a atender os interesses dos alunos de forma a contribuir para sua formação humana.

A coparticipação dos alunos nas decisões acerca "do que, como e para que fazer" Educação Física na escola é fundamental para transformação das práticas pedagógicas e mais, confere significado ao que se vivencia durante as aulas, visto que seus anseios e necessidades, nesta perspectiva, motivaram e valorizaram a participação nas aulas de Educação Física.

A construção de uma identidade seguida de legitimação da Educação Física no Ensino Médio deve se constituir como um grande desafio para os que com ela estão comprometidos. Ressaltamos a importância do investimento na formação profissional continuada do professor, na busca de desenvolver competências que qualifiquem a 
intervenção pedagógica de forma interdisciplinar, reconhecendo a relevância dos saberes e práticas dos alunos jovens de Mato Grosso e de outras regiões do país.

\title{
SPACE OF PHYSICAL EDUCATION AT SCHOOL: A STUDY OF THE CONTENTS OF CLASSES IN HIGH SCHOOL
}

\begin{abstract}
This research investigated the expectations of students at a public school in the state of Mato Grosso in relation to the contents taught in physical education classes in high school. We employed a qualitative descriptive approach with the analysis of the teacher's syllabus, lessons observations and semistructured questionnaires. The results revealed the devaluation of the discipline at school, point to the need for reflection on curriculum and methodological possibilities to be undertaken in physical education classes in high school in order to contemplate the interests and needs of the students.
\end{abstract}

Keywords: Expectations. Physical Education. High School.

\section{EL ESPACIO DE LA EDUCACIÓN FÍSICA EN LA ESCUELA: UN ESTUDIO SOBRE LOS CONTENIDOS DE LAS CLASES EN LA ESCUELA SECUNDARIA}

\begin{abstract}
Resumen
La investigación investigó las expectativas de los alumnos una escuela del estado de Mato Grosso en relación a los contenidos impartidos en las clases de Educación Física en la escuela secundaria. Empleamos el enfoque descriptivo cualitativo con el análisis del plan de enseñanza de la profesora, observaciones de clase y cuestionarios semi-estructurados. Los resultados revelan la desvalorización de la disciplina en la escuela, apuntan a la necesidad de una reflexión sobre posibilidades del currículo y metodológicas que se realizarán en las clases de Educación Física en la escuela secundaria con el fin de contemplar los intereses y necesidades de los estudiantes.

Palabras clave: Expectativas. Educación Física. Escuela Secundaria.
\end{abstract}

\section{Referências}

BOAVENTURA, E. Educação física para a autonomia: construção de possibilidades metodológicas. 2007. 138f. Dissertação (Mestrado em Motricidade Humana) - Instituto de Biociências, Universidade Estadual Paulista, Rio Claro, 2007.

BOSSLE, F. Planejamento de ensino na educação física: uma contribuição ao coletivo docente. Movimento, Porto Alegre, RS, v. 8, n. 1, jan./ abr., 2002. p. 31-39.

BRASIL, Ministério da Educação. Secretaria de Educação Básica. Ensino médio inovador. Brasília, DF: Ministério da Educação, 2009.

BRASIL, Ministério da Educação. Secretaria de Educação Média e Tecnológica. Orientações curriculares para o ensino médio. Brasília, DF: Ministério da Educação, 2006. Disponível em: <http://portal.mec.gov.br/seb/arquivos/pdf/book_volume_01_internet.pdf>. Acesso em: 25 set. 2014. 
CARLAN, P.; KUNZ, E.; FENSTERSEIFER, P. E. O esporte como conteúdo da educação física escolar: estudo de caso de uma prática pedagógica "inovadora". Movimento, Porto Alegre, v. 18, n. 4, out./ dez., 2012. p. 55-75.

DARIDO, S. C. Educação física na escola: implicações para a prática pedagógica. Rio de Janeiro: Guanabara Koogan, 2005.

DAYRELL, J. T. A escola "faz" as juventudes? reflexões em torno da socialização juvenil. Educação e sociedade, Campinas, v. 28, n. 100, especial, out., 2007. p. 1105-1128.

KUNZ, E. Transformação didático-pedagógica do esporte. 6. ed. Ijuí: Unijuí, 2004.

MATO GROSSO. Secretaria de Estado de Educação de Mato Grosso. Orientações curriculares: área de linguagens: educação básica. Cuiabá: SEDUC, 2010.

MINAYO, M. C. S. O desafio da pesquisa social. In: MINAYO, M. C. S. (Org.). Pesquisa social: teoria, método e criatividade. 28. ed. Petrópolis: Vozes, 2009, p. 9-29.

MOREIRA, E. C.; PEREIRA, R. S.; LOPES, Tomires Campos. Indicativos que justificam uma educação física participada e planejada: uma investigação no ensino médio. Coleção pesquisa em educação física, Jundiaí, SP, v. 8, n. 2, 2009. p. 137-144.

MOREIRA, W. W.; SIMÕES, R. M. R.; MARTINS, I. C. Aulas de educação física no ensino médio. 5. ed. Campinas: Papirus, 2014.

PALMA, Alexandre. Educação física, corpo e saúde: uma reflexão sobre outros "modos de olhar". Revista brasileira de ciências do esporte, Campinas, v. 22, n. 2, jan., 2001. p. 23-39.

PALMA, A. P. T. V.; OLIVEIRA, A. A. B.; PALMA, J. A. V. Educação física e a organização curricular: educação infantil, ensino fundamental, ensino médio. 2. ed. Londrina: EdUEL, 2010.

SANTIN, Silvino. Educação física: uma abordagem filosófica da corporeidade. 2.ed. rev. Ijuí: Unijuí, 2003.

TOLEDO, E. de; VELARDI, M.; NISTA-PICCOLO, V. L. O quê ensinar nas aulas de Educação Física? In: MOREIRA, E. C.; NISTA-PICCOLO, V. L. (Org.). O quê e como ensinar educação física na escola. Jundiaí: Fontoura, 2009, p. 27-62.

VAGO, T. M. Pensar a educação física na escola: para uma formação cultural da infância e da juventude. Cadernos de formação RBCE, Campinas, v. 1, n . 1, set. 2009. p. 25-42. 
Recebido em: 09/03/2015

Revisado em: 08/06/2015

Aprovado em: 03/09/2015

Endereço para correspondência:

alecordovil@hotmail.com

Alenir de Pinho Romoaldo Cordovil

Universidade Federal de Mato Grosso, Instituto de Educação.

Av. Fernando Correa da Costa, s/n

Coxipó

78060-900 - Cuiaba, MT - Brasil 